\title{
MALE SEX HORMONES RESPONSE AFTER A MONTH-LONG HIMALAYAS TREK IN RELATION TO HEMOGLOBIN OXYGEN SATURATION
}

\author{
Lana Ružić1, Maja Cigrovski Berković², Hrvoje Starčević \\ Dražen Lovrićc ${ }^{4}$ and Branka R. Matković ${ }^{1}$ \\ ${ }^{1}$ Dpt. Sport and Exercise Medicine, Faculty of Kinesiology, University of Zagreb, Croatia \\ ${ }^{2}$ Department for Endocrinology, Diabetes and Metabolism, University Hospital Centre \\ "Sestre milosrdnice", Zagreb, Croatia \\ ${ }^{3}$ Private practice Dr. Starcevic, Zagreb, Croatia \\ ${ }^{4}$ Special Hospital for Orthopaedic Surgery Akromion, Krapinske Toplice, Croatia
}

Original scientific paper

https://doi.org/10.26582/k.50.2.18

UDC: $612.014: 528.716 .2$

\begin{abstract}
:
High-altitude tourism is becoming increasingly popular among non-athletic population, but its potential impact on health is often neglected. This study investigated the changes in male sex hormones after the trek at altitudes between $1400 \mathrm{~m}$ and $6476 \mathrm{~m}$. Seventeen recreational lowland men (age $48 \pm 11$ years) participated in a 26-day Himalayan trek, with the highest point reached being Mera Peak. The initial measurements were performed 10 days before departure and included blood tests (total testosterone, sex hormone-binding globulin - SHBG, dehydroepiandrosterone sulfate - DHEA-S, follicle stimulating hormone - FSH, and luteinizing hormone - $\mathrm{LH}$ ) and ergometry on a treadmill. The final measurements were done $24 \mathrm{~h}$ after the return to $122 \mathrm{~m}$ (four days after reaching the altitude of $4300 \mathrm{~m}$, and eight days after the altitude of $6476 \mathrm{~m}$ ). During the tour, $\mathrm{SpO}_{2}$ and heart rate were measured 21 times. An increase in SHBG (42.6 \pm 10.6 to $50.7 \pm 12.0$ $\left.\mathrm{nmol} \cdot \mathrm{L}^{-1} ; \mathrm{p}=.011\right)$, and subsequent decrease in calculated free testosterone $(1.8 \pm 0.3$ to $1.6 \pm 0.3 \% ; \mathrm{p}=.003)$ were observed. There was a significant correlation between the relative testosterone decrease and SHBG with mean $\mathrm{SpO}_{2}$ (Spearman $\mathrm{R}=-0.64$ and 0.41 , respectively). LH and FSH increased significantly (FSH Median/ $\mathrm{IQR}$ before $=3.9 / 3.1-5.4$ and after 4.6/4.0-7.1 IU $\cdot \mathrm{L}^{-1} ; \mathrm{p}=.001$ and $\mathrm{LH}$ Median/IQR before=4.8/3.1-5.2 and after 5.9/4.9-9.3 IU $\left.\cdot \mathrm{L}^{-1} ; \mathrm{p}=.008\right)$. The changes in LH and FSH did not correlate with $\mathrm{SpO}_{2}$, whereas the physical fitness levels (expressed in MET) did. The pituitary-adrenal-gonadal axis was affected by the altitude trek (involving physical exertion and hypoxia in combination), but the origin, duration and impact of changes in various aspects of men's health should be further investigated.
\end{abstract}

Key words: altitude, gonadotropins, testosterone, hypoxia

\section{Introduction}

In recent years the high-altitude tourism is becoming increasingly popular even among the so-called non-athletic population. Apart from the known effects of high altitude on cardiovascular parameters, the altitude hypoxia may have an influence on other body systems such as endocrine and reproductive ones, and vice-versa, the endocrine system has been proposed as an important regulator of the high-altitude adaptation process. Changes in the sex hormones at high altitudes have been investigated only scarcely, and usually not in recreational population. There are suggestions of the free testosterone decrease at altitude and, according to current literature, adaptation to high altitudes might include lower serum testosterone levels, which protect against elevated hemoglobin levels and chronic mountain sickness (Marinelli, Roi, Giacometti, Bonini, \& Banfi, 1994), but there is no evidence of a dose-response relationship and how soon after the initial exposure the acclimatization may start. On the other hand, an acute exposure to hypoxia leads to an increase in testosterone, which, via hypoventilation, protects from acute mountain sickness and respiratory alkalosis (Gonzales, Tapia, Gasco, Rubio, \& GonzalesCastaneda, 2011). Moreover, changes in dehydroepiandrosterone-sulfate (DHEA-S) and its conver- 
sion to testosterone might be important in stressbuffering during stay at altitude (Pontremolesiet, et al., 2012), and it is important for altitude acclimatization (Lee, et al., 2016). The protective effect of DHEA in pulmonary hypertension may be related to artery dilatation response to nitric oxide (Oka, et al., 2017). Additionally, there is an increasing evidence that there might be some rearrangement in neuroendocrine system as it has been proven for chronic exposure (Sadykova \& Dzhunusova, 2018). The stay at high altitude might initially lead to a decrease in serum luteinizing hormone (LH) and testosterone, and an increase in serum folliclestimulating hormone (FSH) level, but there are still some inconsistencies. For example, there is a study showing the increase of LH hormone (Verratti, et al., 2016). It seems that during a prolonged stay at high altitude serum FSH levels decrease, whereas, on the other hand, serum LH and testosterone levels increase (He, et al., 2015). Also, the decrease of plasma testosterone seems to be LH independent (Wang, Tsai, Chen, \& Wang, 2001). As the previous findings were not always consistent, the aim of our study was to investigate the possible effects of a high-altitude trek on male sex hormones in nonathletic male population.

\section{Methods}

The study included 17 adult male non-athletes (originating from the same village, who participated in a 26-day long tour of Himalayas at the end of 2017). Participants provided written informed consent and the study was approved by the Ethics Committee of the Faculty of Kinesiology, University of Zagreb. All study procedures were in accordance with the Declaration of Helsinki.

\section{Initial measurements}

The initial measurements were performed 10 days prior to the departure and included blood tests (total testosterone, sex hormone-binding globulin - SHBG, DHEA-S, FSH and LH) and ergometry on a treadmill. The procedure started in the morning by taking blood samples at 9:30, after 12 hours of fasting, in a laboratory at altitude of 122 $\mathrm{m}$ above the sea level. Following blood sampling, the all-out treadmill test, overseen by cardiologists, was performed according to the standardized Bruce stress test protocol (a graded test till complete exhaustion; Bruce, Kusumi, \& Hosmer, 1973). The goal was to exclude any possible coronary heart diseases, but also to estimate participants' cardiovascular fitness. The treadmill speed and incline increased every three minutes. From the achieved time, treadmill speed and treadmill grade, the maximal aerobic capacity was estimated and expressed in MET (metabolic equivalent of task).

\section{Intervention}

The total duration of the trip was 26 days, day 1 being the day of departure and day 26 the day of return, both by plane. The hike trip could be divided into two parts. During the first part (day 2 to day 13) the participants flew from Kathmandu (at 1400 $\mathrm{m})$ to Lukla (at $2840 \mathrm{~m}$ ) and then hiked to Base Camp (at $5364 \mathrm{~m}$ ) and back to Lukla. The goal of the second part of the trip was to reach Mera Peak, so from day 14 to day 25 they climbed from Lukla to Mera Peak (at $6476 \mathrm{~m}$ ) over Thuli Kharka and High Camp (at $5780 \mathrm{~m}$ ) and again back to Lukla (at $2840 \mathrm{~m}$ ) and finally returned by plane to Kathmandu (at $1440 \mathrm{~m}$ ). The usual daily hiking duration was 5-6 hours.

During the expedition, the peripheral capillary oxygen saturation $\left(\mathrm{SpO}_{2}\right)$ was recorded for about $2 \mathrm{~min}$ by pulse oximetry from the fingertip. The measurements took place during the evening at each newly reached altitude (503 OXY-5 GIMA; Gima S.p.A., Gessate, Italy); $\mathrm{SpO}_{2}$ parameter specifications: measuring range (35-99\%); accuracy ( $2 \%$ during $75-99 \%$, 3\% during 50-74\%). In total, these measurements were taken on 21 occasions, the first one in Phakding (at $2645 \mathrm{~m}$ ) and the last two in Lukla (at $2840 \mathrm{~m}$ ).

Information about any drug consumption and altitude sickness symptoms were also noted. The first day after the return and a night's sleep the laboratory analyses were repeated in the same laboratory and according to the initial protocol.

\section{The final measurements}

The blood tests were repeated, and the measurements were conducted 24 hours after the return from Himalayas in the laboratory at $122 \mathrm{~m}$ altitude. It was eight days after reaching the highest altitude of Mera Peak and four days after a considerable altitude of Zatrwa La.

\section{Blood tests}

The levels of total testosterone, FSH, LH, SHBG and DHEA-S were determined by commercial, fully automated immunoassays (Roche Diagnostics, Switzerland) on Cobas 6000 analyser (Roche Diagnostics, Switzerland). Free testosterone was calculated from total testosterone and SHBG levels using the online available Free \& Bioavailable Testosterone calculator (www.issam.ch/freetesto.htm). According to the normal ranges provided by the immunoassay manufacturer, the reference ranges were as follows: free testosterone 1.2-2.6\%, total testosterone 1.9-7.4 $\mathrm{ng} \cdot \mathrm{mL}^{-1}$, SHBG 19.3-76.4 $\mathrm{nmol} \cdot \mathrm{L}^{-1}$, FSH 1.5-12.4 IU $\cdot \mathrm{L}^{-1}$, DHEA-S 1.2-9.0 $\mu \mathrm{mol} \cdot \mathrm{L}^{-1}, \mathrm{LH}$ 1.7-8.6 IU $\cdot \mathrm{L}^{-1}$. 


\section{Data analysis}

The data were analysed by Statistica for Windows, 13.0. Normality of data distribution was tested by Shapiro Wilks test. Pre- to post-differences were tested by Student $t$-test for dependent samples and Wilcoxon matched pairs test for variables that did not follow normal distribution. Relations between data were analysed by Spearman or Pearson correlation analysis. Data are presented as Mean $\pm \mathrm{SD}$ and Median/IQR for not normally distributed data. The cut-off value for statistical significance was set at $\mathrm{p}<.05$. The post-hoc power was analysed in $\mathrm{G}^{*}$ POWER version 3.1.9.2., a free statistical power program available at http://www. gpower.hhu.de/.

\section{Results}

The mean age of the subjects was $48 \pm 11$ years and the mean body mass index (BMI) $26.5 \pm 2.3 \mathrm{~kg} \cdot \mathrm{m}^{-2}$. The mean heart rate at rest and mean oxygen saturation at each point of measurement during the trip are presented in Table 1. The mean peripheral capillary oxygen saturation decreased with every increase in altitude (Figure 1).

Table 1. The heart rate values at rest (HRrest) and the peripheral capillary oxygen saturation $\left(\mathrm{SpO}_{2}\right)$ presented as Mean $\pm S D$ on each of the 21 locations at which the data were collected

\begin{tabular}{lcc}
\hline Location of measurement & $\begin{array}{c}\text { HRrest } \\
\text { (bpm) } \\
\text { Mean } \pm \text { SD }\end{array}$ & $\begin{array}{c}\mathrm{SpO}_{2}(\%) \\
\text { Mean } \pm \mathrm{SD}\end{array}$ \\
\hline Phakding (2645m) & $83.5 \pm 13.3$ & $91.9 \pm 0.9$ \\
Namche Bazaar (3440m) & $75.9 \pm 14.1$ & $89.6 \pm 2.3$ \\
Kumjung (3700m) & $74.1 \pm 10.7$ & $89.3 \pm 3.0$ \\
Thyangboche (3870m) & $79.4 \pm 12.3$ & $89.7 \pm 3.1$ \\
Dingboche (4360m & $83.9 \pm 14.2$ & $85.9 \pm 3.9$ \\
Dongla (4930) & $71.3 \pm 10.3$ & $83.9 \pm 4.8$ \\
Gorak Shep (5170 m), & $80.3 \pm 12.2$ & $79.6 \pm 5.7$ \\
after Base camp (5335m) & $72.5 \pm 12.1$ & $85.5 \pm 5.4$ \\
Pheriche (4280m) & $70.2 \pm 11.3$ & $91.6 \pm 1.6$ \\
Namche Bazaar (3440m) & $75.7 \pm 12.0$ & $92.9 \pm 2.1$ \\
Lukla (2840). & $75.6 \pm 10.0$ & $91.5 \pm 3.2$ \\
Chutanga (3020m) & $75.2 \pm 10.5$ & $90.0 \pm 2.8$ \\
Thuli Kharka (4300m) & $75.3 \pm 10.4$ & $92.5 \pm 1.9$ \\
Khote (3660 m) & $79.2 \pm 12.5$ & $89.4 \pm 3.6$ \\
Thangnag (4356m) & $72.1 \pm 9.1$ & $84.9 \pm 3.9$ \\
Khare (5045m) & $95.5 \pm 12.9$ & $74.6 \pm 6.6$ \\
High Camp (5780m) & $95.3 \pm 10.7$ & $81.2 \pm 5.3$ \\
Khare (5045m), after Mera & $82.3 \pm 9.8$ & $90.6 \pm 2.9$ \\
Peak (6464m) & $77.4 \pm 10.0$ & $88.3 \pm 3.9$ \\
Khote (3660m) & $71.9 \pm 12.1$ & $93.5 \pm 2.7$ \\
Thuli Kharka (4300m) & $66.3 \pm 10.0$ & $94.3 \pm 1.9$ \\
Lukla (2840m), over Zatrwa La & & \\
(4610m) & & \\
Lukla (2840m) & & \\
\hline
\end{tabular}

The statistically significant changes were observed in repeated measures of SHBG and calculated free testosterone. While the mean SHBG increased (from $42.6 \pm 10.6$ to $50.7 \pm 12.0 \mathrm{nmol} \cdot \mathrm{L}^{-1}$; $\mathrm{p}=.011$ ), the mean free testosterone decreased (from $1.8 \pm 0.3$ to $1.6 \pm 0.3 \%$; $\mathrm{p}=.003$; Table 2 ).

The individual responses and the pre- and postascent values of SHBG and free testosterone for each participant are shown in Figures 2 and 3.

In the next step the changes in free testosterone and SHBG were expressed as delta values (percentages). There was a high correlation between the increase in SHBG and the decrease in free testosterone (Spearman $\mathrm{r}=0.79 ; \mathrm{p}<.05$ ), which was expected. The correlation between the relative free testosterone decreases and $\mathrm{SpO}_{2}$ was significant (Spearman correlation coefficient $\mathrm{r}=0.41 ; \mathrm{p}<.05$, Figure 4); the higher the mean $\mathrm{SpO}_{2}$ levels during the trip, the less the free testosterone decrease was found. Also, the peripheral capillary oxygen saturation significantly negatively correlated with the increase in SHBG $(r=-0.64 ; \mathrm{p}<.05)$.

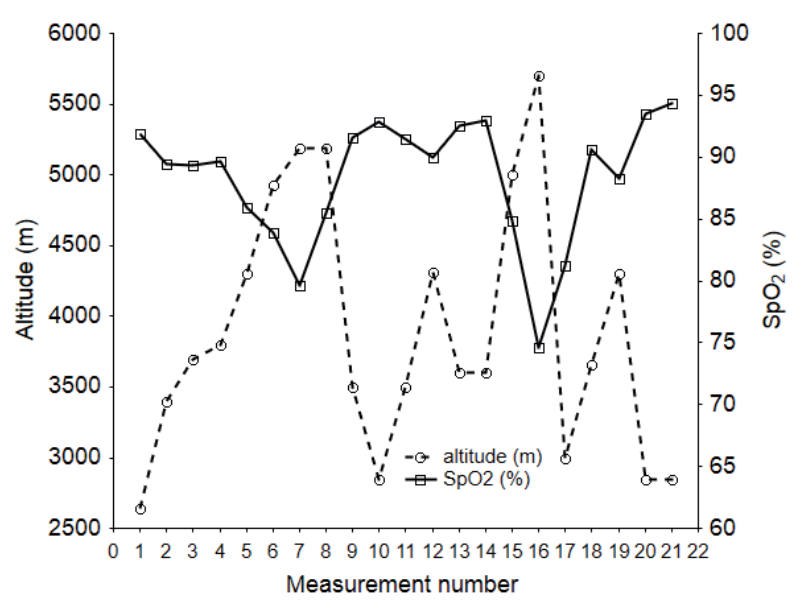

Figure 1. Altitudes reached during the trek and mean peripheral capillary oxygen saturation $\left(\mathrm{SpO}_{2}\right)$.

Table 2. The results of the Student t-test for dependent samples (before-to-after differences in sex hormones)

\begin{tabular}{|c|c|c|c|}
\hline & Mean $\pm S D$ & $t$ & $\mathrm{p}$ \\
\hline SHBG - before $\left(\mathrm{nmol} \cdot \mathrm{L}^{-1}\right)$ & $42.6 \pm 10.6$ & & \\
\hline SHBG - after $\left(\mathrm{nmol} \cdot \mathrm{L}^{-1}\right)$ & $50.7 \pm 12.0$ & -2.9 & .011 \\
\hline $\begin{array}{l}\text { Total testosterone - } \\
\text { before }\left(\mathrm{ng} \cdot \mathrm{mL}^{-1}\right)\end{array}$ & $4.2 \pm 1.3$ & & \\
\hline $\begin{array}{l}\text { Total testosterone - } \\
\text { after }\left(\mathrm{ng} \cdot \mathrm{mL}^{-1)}\right.\end{array}$ & $4.5 \pm 0.7$ & -0.9 & .401 \\
\hline $\begin{array}{l}\text { DHEA-S - before } \\
\left(\mu \mathrm{mol} \cdot \mathrm{L}^{-1}\right)\end{array}$ & $5.0 \pm 3.0$ & & \\
\hline DHEA-S - after $\left(\mu \mathrm{mol} \cdot \mathrm{L}^{-1}\right)$ & $5.7 \pm 3.0$ & -1.2 & .236 \\
\hline $\begin{array}{l}\text { Free testosterone - } \\
\text { before }(\%)\end{array}$ & $1.8 \pm 0.3$ & & \\
\hline $\begin{array}{l}\text { Free testosterone - } \\
\text { after }(\%)\end{array}$ & $1.6 \pm 0.3$ & 3.5 & .003 \\
\hline
\end{tabular}




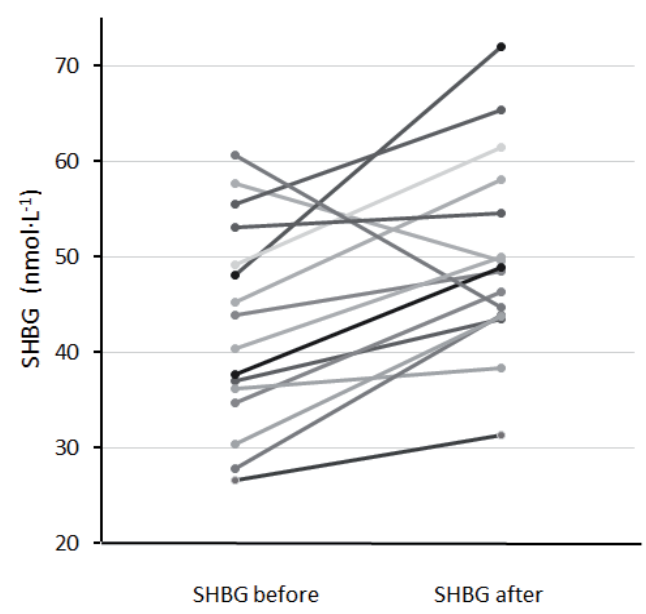

Figure 2. Individual changes in $S H B G$.

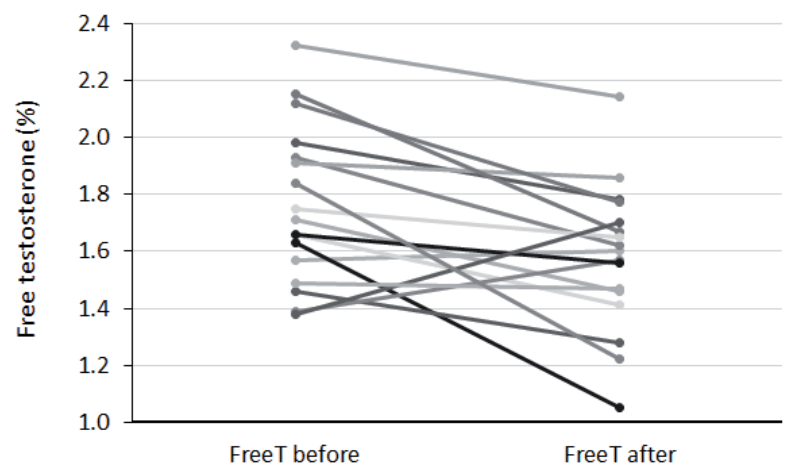

Figure 3. Individual changes in free testosterone.

For not-normally distributed parameters, pituitary hormones LH and FSH, the changes were determined by $\mathrm{C}$ (Table 3 ).

The relative changes in LH, FSH and SHBG (percentage of change) were also tested in relation to mean peripheral capillary oxygen saturation using nonparametric Spearman rank correlation, but no significant correlations were found for either LH $(r=0.321)$ or FSH $(r=-0.329)$.

The ratios free testosterone/DHEA-S and total testosterone/DHEA-S were calculated for the initial and final testing and the change in ratios was tested by the Wilcoxon matched pairs test. There was no change in the total testosterone/DHEA-S ratio after the expedition, but a significant decrease in the free testosterone/DHEA-S ratio was observed (median before $=0.37$ vs. median after $=0.30 ; \mathrm{t}=3.0, \mathrm{z}=3.4$; $\mathrm{p}<.001)$.

As the subjects had executed the all-out Bruce treadmill test protocol before the expedition, the

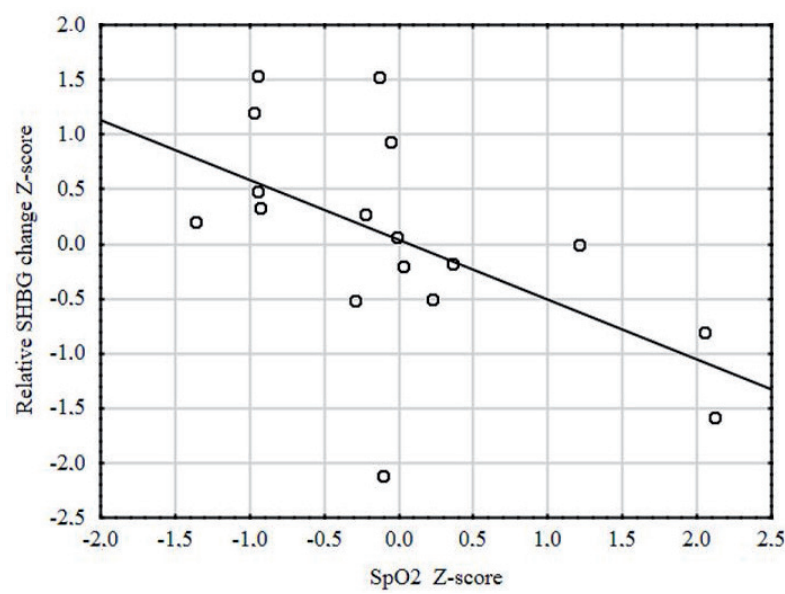

Figure 4. The line plot represents peripheral capillary oxygen saturation during the trip $\left(\mathrm{SpO}_{2}\right)$ and the relative change in SHBG for 17 participants.

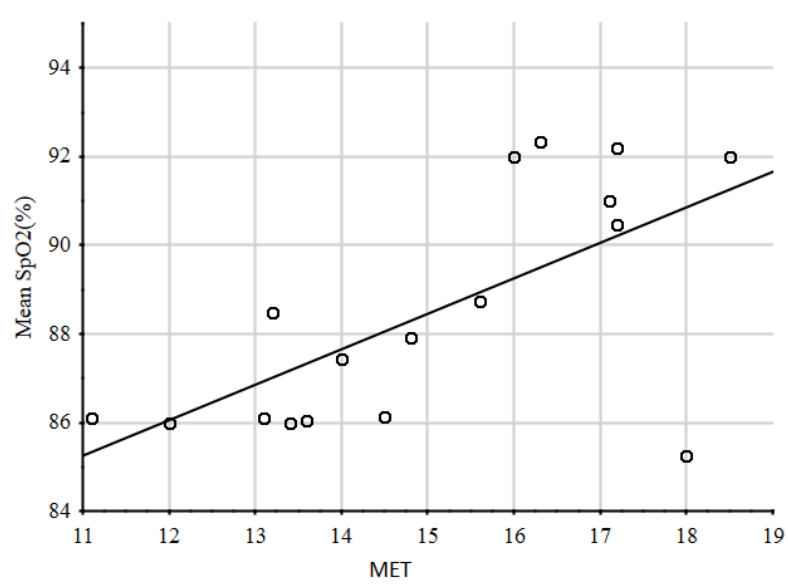

Figure 5. Correlation between the maximal intensity in MET achieved by Bruce treadmill protocol and the peripheral capillary oxygen saturation $\left(\mathrm{SpO}_{2}\right)$ during the trek.

intensity achieved at maximal exertion (expressed in MET) was correlated with peripheral capillary oxygen saturation. The correlation was significant, which suggested that higher peripheral capillary oxygen saturations, expressed as mean values for each participant during the trek, were seen in the participants achieving higher intensities on the exertion test (Pearson $r=0.713$ at $p<.05$; Figure 5).

\section{General health and drug usage}

Even though most subjects expectedly reported feelings of strong exhaustion at higher altitudes, the overall occurrence of health-related symptoms and drug usage was relatively low. Seven out of

Table 3. Changes in LH and FSH concentrations before and after the expedition (data are presented as Median and $1^{\text {st }}$ to $3^{r d}$ quartile range (IQR)

\begin{tabular}{lccccc}
\hline & $\begin{array}{c}\text { Before } \\
\text { median/IQR }\end{array}$ & $\begin{array}{c}\text { After } \\
\text { median/IQR }\end{array}$ & $t$ & $z$ & $p$ \\
\hline FSH $\left(I U \cdot \mathrm{L}^{-1}\right)$ & $3.9 / 3.1-5.4$ & $4.6 / 4.0-7.1$ & 0.00 & 3.40 & .001 \\
$\mathrm{LH}\left(\mathrm{IU} \cdot \mathrm{L}^{-1}\right)$ & $4.8 / 3.1-5.2$ & $5.9 / 4.9-9.3$ & 0.00 & 2.66 & .008 \\
\hline
\end{tabular}


17 participants did not report any health-related problems when asked about headache, vertigo, dizziness, appetite, severe respiratory symptoms, and insomnia. Of the remaining 10 participants, seven reported occasional mild headaches and two moderate-to-severe headache. More than half of the participants reported occasional insomnia and there was only one case of diarrhea. Most of the health-related problems were reported during the first part of the journey. Symptoms started from day 5 to day 12 (at altitudes from $3440 \mathrm{~m}$ to 5360 $\mathrm{m}$ and back to $3440 \mathrm{~m}$ ). During the second part of the trek (day 13 to day 26 from $3440 \mathrm{~m}$ to $6476 \mathrm{~m}$ and back to $1440 \mathrm{~m}$ ), there were even less adverse events, that is only five reported headaches. Most of those occurred at High Camp (5780 m) and after climbing to Mera Peak (6476 m). Also, one person coughed and five had sore throat, both symptoms seemingly unrelated to mountain sickness but rather to acute respiratory infection.

No one used acetazolamide, but they consumed 24 tablets of Caffetin (which is over-the-counter combination of paracetamol $250 \mathrm{mg}$, propyphenazone $210 \mathrm{mg}$, caffeine $50 \mathrm{mg}$ and codeine phosphate $10 \mathrm{mg}$ ), five capsules of ibuprofen $400 \mathrm{mg}$, five tablets of Aspirin plus $\mathrm{C}$ and 20 sore throat lozenges altogether during the journey.

\section{Power analysis}

The achieved power for the main finding, SHBG increase was Power $=0.87$ with a medium-to-high effect size $\mathrm{d}=0.70$ and $\alpha$ error probability of 0.05 .

\section{Discussion and conclusion}

The aim of the study was to detect changes in sex hormones in non-athletic male participants after the Himalayan trek. The main observed finding that persisted after the trek was the increase in SHBG, which might be explained by the demands of physical activity that participants were exposed to. A recently published study suggests that higher SHBG might be associated with lower hematocrit and symptoms of hypogonadism, irrespective of testosterone level, and implies the importance of not only testosterone production but its biological activity (Behan \& Kinkead, 2001). In our study we did not find any changes in total testosterone level after the trek. On the other hand, the calculated free testosterone, most probably based on the changes in SHBG, appeared to have been reduced after the expedition. The decrease in free testosterone is consistent with previous findings (Wang, et al., 2001). Only one subject had a very different response: the opposite direction of changes of both SHBG and free testosterone than others. In his case the increase in free testosterone and decrease of SHBG occurred for unknown reasons. He was not much different from others in any known way; his fitness level was good, although not the best in the group. Another less noticeable exception was also one participant who had a decrease in SHBG, whereas all the others had increases in SHBG and decreases in free testosterone.

The correlation between the relative changes (the percentage of change) in SHBG and free testosterone with mean $\mathrm{SpO}_{2}$ during the trek was significant. That might imply hypoxia-related causes of those changes, but the blood samples in this study were not taken during the trek and at the same time as $\mathrm{SpO}_{2}$. That is why the hypoxia could not be named with certainty as the cause of these changes, although the testosterone was previously found to be affected by hypoxia and had its receptors in respiratory centers (Behan \& Kinkead, 2001).

An increase in DHEA-S was not significant; in some participants it increased two or even three times, but in some it decreased or stayed similar. There are indications that the increase in DHEA-S might depend on its sea level values, meaning that the higher increase should be expected in those with lower see level concentrations of DHEA-S (Lee, et al., 2006), but this was not the case in this study. Still, the ratio between free testosterone/DHEA-S significantly decreased, which was mostly due to the free testosterone decrease. The similar finding was previously reported (Gonzales, et al., 2011) and the observed decrease in the free testosterone/ DHEA-S ratio was explained as a part of adaptation process to hypoxia, with beneficial effects on prevention of mountain sickness, since DHEA-S is an important source of testosterone through the activity of 17beta-hydroxysteroid dehydrogenase.

A slow conversion to testosterone might have a role in mountain sickness prevention (Gonzales, Tapia, Gasco, \& Gonzales-Castaneda, 2012) and it was reported that in case of a poor acclimatization to high altitude, the conversion of DHEA-S to testosterone was increased, leading to excessive erythrocytosis (Gonzales, 2013). The testosterone alone seems to impact growth factor and act directly on bone marrow, which leads to accelerated erythropoiesis (Zitzmann, 2018), while in synergy with erythropoietin it might increase hemoglobin by improving iron bioavailability (Bachman, et al., 2014). The physiological role of the decreased ratio of free testosterone/DHEA-S in acute mountain sickness is still unclear.

Gonadal hormones are key factors in reproductive capacity, but also in the neural control of respiration. In women, administrated testosterone increased ventilatory sensitivity and altered apneic threshold (Ahuja, Mateika, Diamond, \& Badr, 2007; Zhou, Rowley, Demirovic, Diamond, \& Badr, 2003), which indicated that lower testosterone might be beneficial in preventing hyperventilation. There are indications that inhibition of testosterone might lead to the increased $\mathrm{CO}_{2}$ reserve and better breathing stability when at sea 
level. It might only be speculated that lower testosterone might also reduce hyperventilation at altitude possibly affecting the extent of acute mountain sickness symptoms provoked by alkalosis (Chowdhuri, Bascom, Mohan, Diamond, \& Badr, 2013).

Both regulatory pituitary hormones, LH and $\mathrm{FSH}$, increased significantly in this study. A similar increase in LH after altitudes hike was observed in a Kilimanjaro expedition (Verratti, et al., 2016) as the reported LH levels after the trek significantly increased, but in that study, there was no significant change in FSH and total testosterone. Also, in case of low testosterone, LH levels might increase via a negative feedback loop (Veldhuis, Bae, Swerdloff, Iranmanesh, \& Wang, 2005), whereas an increase in FSH was related to endurance training (Vasankari, Kujala, Heinonen, \& Huhtaniemi, 1993). Currently, there is still no consensus on how physical activity might alter hypotalamo-pituitary-testicular axis. Some data suggest that endurance training might affect testosterone levels, usually in a negative way (decrease) and at the same time FSH levels are higher and mentioned changes imply compensatory hypogonadism as a result (Vaamonde, GarciaManso, \& Hackney, 2017). According to research, heavy training lasting for several weeks leads to a decrease in the free testosterone/cortisol and free testosterone/SHBG ratio (Urhausen, Kullmer, \& Kindermann, 1987; Vervoorn, et al., 1991).

A very interesting finding was that the mean peripheral capillary oxygen saturation observed during the trek strongly correlated with the intensity level (expressed in MET) that participants achieved on a treadmill ergometry during the initial physical exam. No similar findings were reported before; usually, physical fitness was investigated in relation to mountain sickness symptoms (Milledge, et al., 1991).

The overall usage of drugs was not high. No subjects used acetazolamide to prevent or reduce symptoms of mountain sickness. Literature showed no evidence that the drugs that were used might influence the results. The consumed drugs were not found to be listed as potential interfering substances with laboratory methods used in the detection of either gonadotrophins, testosterone, DHEA-S, or SHBG. In literature, only one study in humans shows possible influence of ibuprofen on testosterone, but in that study $1200 \mathrm{mg}$ were taken daily for six weeks, while our subjects used altogether $2000 \mathrm{mg}$ (five capsules used by three participants) during the whole study. To the best of our knowledge the used drugs, especially if taken sporadically like in this study, should not interfere with the hypothalamic-pituitary-gonadal axis (Kristensen, et al., 2018).

The limitation of the study was a lack of possibility to take blood sample every day during the trek, but this is a problem encountered in similar studies executed under specific conditions. The hormone data and saturation data were not taken at the same time points, so the hormone changes and relations to hemoglobin oxygen saturation should, for now, be cautiously interpreted. The study design including the trek and exposure to high altitude for almost a month had a limitation due to the number of subjects who could be involved. The obtained power (0.87) for the selected sample ensures the probability to detect standardized effect size of 0.7 for SHBG and the mean observed relative increase in SHBG was 20\%. In addition, free testosterone decreased for $12 \%$. No month-to-month variations in free testosterone were found previously (Tancredi, Reginster, Luyckx, \& Legros, 2005), so this change might be considered as a result of SHBG change caused by the trek. Still, it was stated previously that SHBG might be linked to androgen deficiency features independently of total testosterone (Rastrelli, Corona, Cipriani, Mannucci, \& Maggi, 2018).

Another limitation of the study is the problem of separating the altitude and exercise effects. Several recent studies on exercise and male sex hormones reported a decrease of SHBG and increase of testosterone or free testosterone (Grandys, et al., 2009; Hayes, Herbert, Sculthorpe, \& Grace, 2017; Lovell, Cuneo, Wallace, McLellan, 2012; Sellami, et al., 2018), which is the opposite direction of changes than the observed in our study, or no changes at all (Simao, et al., 2013). According to the self-perceived exertion of the participants, the exercise intensity was not very high on most of the days. Considering that, it seems that the altitude stay might have had an independent influence which was stronger than the exercise (hike) effect.

The SHBG increase was observed as well as an increase in LH and FSH. The mechanism of the noticed changes is speculative, and further mechanistic studies are needed. The decrease in the free testosterone/DHEA-S ratio might be indicative of high physiological demands of the trek and might be due to slower conversion of DHEA-S to testosterone and not only altitude-related. The evidence exists that exposure to endurance exercise training might alter reproductive hormonal profile, mainly low resting testosterone levels in some men (Hackney \& Aggon, 2013), the condition named as "exercise induced hypogonadism" (Hackney, Moore, \& Brownlee, 2005).

There is a lack of clear knowledge about the health-related consequences after a recent hypoxia exposure in men, but it seems that different inherent parameters of physical activity (training volume, intensity, frequency and environment) are of paramount importance. Altitude training is an environment in which different adoptive endocrinological processes might have a health-related role. The decrease in free testosterone might be related to depression, lack of energy, infertility and erectile dysfunction, but the extent of the decrease found 
in this study might not be large enough or lasting long enough to cause any impact on those symptoms. The high-altitude trek might also have positive effects on health. Higher levels of SHGB and lower levels of testosterone were shown to be related to lower risk of diabetes and metabolic syndrome (Li, Ford, Li, Giles, \& Liu S, 2010), but the dura- tion of the SHBG change found in this study is unknown. The future studies are needed in order to investigate the duration of the observed changes and their positive and negative health implications, as the number of trekkers undertaking trips at very high altitudes to the Himalayas, Andes or Mount Kilimanjaro is increasing.

\section{References}

Ahuja, D., Mateika, J.H., Diamond, M.P., \& Badr, M.S. (2007). Ventilatory sensitivity to carbon dioxide before and after episodic hypoxia in women treated with testosterone. Journal of Applied Physiology, 102, 1832-1838. doi: 10.1152/japplphysiol.01178.2006

Bachman, E., Travison, T.G., Basaria, S., Davda, M.N., Guo, W., Li, M., et al. (2014). Testosterone induces erythrocytosis via increased erythropoietin and suppressed hepcidin: Evidence for a new erythropoietin/hemoglobin set point. Journals of Gerontology - Series A Biological Sciences and Medical Sciences, 69(6), 725-735. doi: 10.1093/ gerona/glt154

Behan, M., \& Kinkead, R. (2011). Neuronal control of breathing: Sex and stress hormones. Comprehensive Physiology, 1(4), 2101-2139. doi:10.1002/cphy.c100027

Bruce, R.A., Kusumi, F., \& Hosmer, D. (1973). Maximal oxygen intake and nomographic assessment of functional aerobic impairment in cardiovascular disease. American Heart Journal, 85, 546-552.

Chowdhuri, S., Bascom, A., Mohan, D., Diamond, M.P., \& Badr, M.S. (2013). Testosterone conversion blockade increases breathing stability in healthy men during NREM sleep. Sleep, 36(12), 1793-1798. doi:10.5665/sleep.3202

Gonzales, G.F. (2013). Serum testosterone levels and excessive erythrocytosis during the process of adaptation to high altitudes. Asian Journal of Andrology, 15(3), 368-374. doi:10.1038/aja.2012.170

Gonzales, G.F., Tapia, V., Gasco, M., \& Gonzales-Castaneda, C. (2012). Aromatase activity after a short course of letrozole administration in adult men at sea level and at high altitude (with and without excessive erythrocytosis). Hormone and Metabolic Research, 44, 140-145. doi: 10.1055/s-0031-1301280

Gonzales, G.F., Tapia, V., Gasco, M., Rubio, J., \& Gonzales-Castaneda, C. (2011). High serum zinc and serum testosterone levels were associated with excessive erythrocytosis in men at high altitudes. Endocrine, 40, 472-480. doi.org/10.1007/s12020-011-9482-1

Grandys, M., Majerczak, J., Duda, K., Zapart-Bukowska, J., Kulpa, J., \& Zoladz, J.A. (2009). Endurance training of moderate intensity increases testosterone concentration in young, healthy men. International Journal of Sports Medicine, 30(7), 489-495. doi: 10.1055/s-0029-1202340

Hackney, A., \& Aggon, E. (2018). Chronic low testosterone levels in endurance trained men: The exercise-hypogonadal male condition. Journal of Biochemistry and Physiology, 1(1), 103.

Hackney, A.C., Moore, A.W., \& Brownlee, K.K. (2005). Testosterone and endurance exercise: Development of the exercisehypogonadal male condition. Acta Physiologica Hungarica, 92, 121-137. doi.org/10.1556/APhysiol.92.2005.2.3

Hayes, L.D., Herbert, P., Sculthorpe, N.F., \& Grace, F.M. (2017). Exercise training improves free testosterone in lifelong sedentary aging men. Endocrine Connections, 6(5), 306-310. doi: 10.1530/EC-17-0082

He, J., Cui, J., Wang, R., Gao, L., Gao, X., Yang, L., et al. (2015). Exposure to hypoxia at high altitude (5380 m) for 1 year induces reversible effects on semen quality and serum reproductive hormone levels in young male adults. High Altitude Medicine and Biology, 16(3), 216-222. doi: 10.1089/ham.2014.1046

Kristensen, D.M., Desdoits-Lethimonier, C., Mackey, A.L., Dalgaard, M.D., De Masi, F., Munkbøl, C.H., et al. (2018). Ibuprofen alters human testicular physiology to produce a state of compensated hypogonadism. Proceedings of the National Academy of Sciences of the USA, 115(4), E715-E724. doi.org/10.1073/pnas.1715035115

Lee, W.C., Chen, S.M., Wu, M.C., Hou, C.W., Lai, Y.C., Laio, Y.H., et al. (2006). The role of dehydroepiandrosterone levels on physiologic acclimatization to chronic mountaineering activity. High Altitude Medicine and Biology, 7(3), 228-236. doi: 10.1089/ham.2006.7.228

Li, C., Ford, E.S., Li, B., Giles, W.H., \& Liu, S. (2010). Association of testosterone and sex hormone-binding globulin with metabolic syndrome and resistance in men. Diabetes Care, 33(7), 1618-1624. doi: 10.2337/dc09-1788

Lovell, D.I., Cuneo, R., Wallace, J., \& McLellan, C. (2012). The hormonal response of older men to sub-maximum aerobic exercise: The effect of training and detraining. Steroids, 77(5), 413-418. doi: 10.1016/j.steroids.2011.12.022

Marinelli, M., Roi, G.S., Giacometti, M., Bonini, P., \& Banfi, G. (1994). Cortisol, testosterone, and free testosterone in athletes performing a marathon at 4,000 m altitude. Hormone Research, 41(5-6), 225-229.

Milledge, J.S., Beeley, J.M., Broome, J., Luff, N., Pelling, M., \& Smith, D. (1991). Acute mountain sickness susceptibility, fitness and hypoxic ventilatory response. European Respiratory Journal, 4(8), 1000-1003.

Oka, M., Karoor, V., Homma, N., Nagaoka, T., Sakao, E., Golembeski, S.M., et al. (2007). Dehydroepiandrosterone upregulates soluble guanylate cyclase and inhibits hypoxic pulmonary hypertension. Cardiovascular Research, 74(3), 377-387. doi: 10.1016/j.cardiores.2007.01.021 
Pontremolesi, S., Biselli, R., Ciniglio Appiani, G., D’Amelio, R., Simona, S., \& Patacchioli, F.R. (2012). Acute hypobaric-hypoxia challenge and salivary cortisol and DHEA-S in healthy male subjects. Aviation, Space, and Environmental Medicine, 83(7), 637-642. doi: 10.3357/ASEM.3080.2012

Rastrelli, G., Corona, G., Cipriani, S., Mannucci, E., \& Maggi, M. (2018). Sex hormone-binding globulin is associated with androgen deficiency features independently of total testosterone. Clinical Endocrinology (Oxf), 88(4), 556-564. doi: 10.1111/cen.13530

Sadykova, G., \& Dzhunusova, G. (2018). Rearrangement of neuroendocrine systems in the mountains. Wilderness and Environmental Medicine, 28(1), e2. doi: 10.1016/j.wem.2017.01.012

Sellami, M., Dhahbi, W., Hayes, L.D., Kuvacic, G., Milic, M., \& Padulo, J. (2018). The effect of acute and chronic exercise on steroid hormone fluctuations in young and middle-aged men. Steroids, 132, 18-24. doi: 10.1016/j. steroids.2018.01.011

Simão, R., Leite, R.D., Speretta, G.F., Maior, A.S., de Salles, B.F., de Souza Junior, T.P., et al. (2013). Influence of upperbody exercise order on hormonal responses in trained men. Applied Physiology, Nutrition, and Metabolism, 38(2), 177-181. doi: 10.1139/apnm-2012-0040

Tancredi, A., Reginster, J.Y., Luyckx, F., \& Legros, J.J. (2005). No major month to month variation in free testosterone levels in aging males. Minor impact on the biological diagnosis of 'andropause'. Psychoneuroendocrinology, 30(7), 638-646. doi: 10.1016/j.psyneuen.2005.02.002

Urhausen, A., Kullmer, T., \& Kindermann, W. (1987). A 7-week follow-up study of the behaviour of testosterone and cortisol during the competition period in rowers. European Journal of Applied Physiology and Occupational Physiology, 56(5), 528-533.

Vaamonde, D., Garcia-Manso, J.M., \& Hackney, A.C. (2017). Impact of physical activity and exercise on male reproductive potential: A new assessment questionnaire. Revista Andaluza de Medicina del Deporte, 10(2), 79-93. doi.org/10.1016/j.ramd.2016.11.017

Vasankari, T.J., Kujala, U.M., Heinonen, O.J., \& Huhtaniemi, I.T. (1993). Effects of endurance training on hormonal responses to prolonged physical exercise in males. Acta Endocrinologica (Copenhagen), 129(2), 109-113.

Veldhuis, J.D., Bae, A., Swerdloff, R.S., Iranmanesh, A., \& Wang, C. (2005). Experimentally induced androgen depletion accentuates ethnicity-related contrasts in luteinizing hormone secretion in Assian and Caucasian men. Journal of Clinical Endocrinology and Metabolism, 90(3), 1632-1638. doi: 10.1210/jc.2004-1362

Verratti, V., Di Giulio, C., D’Angeli, A., Tafuri, A., Francavilla, S., \& Pelliccione, F. (2016). Sperm forward motility is negatively affected by short-term exposure to altitude hypoxia. Andrologia, 48(7), 800-806. doi: 10.1111/ and.12515

Vervoorn, C., Quist, A.M., Vermulst, L.J.M., Erich, W.B.M., De Vries, W.R, \& Thijssen, J.H.H. (1991). The behaviour of the plasma free testosterone/cortisol ratio during a season of elite rowing training. International Journal of Sports Medicine, 12(3), 257-263.

Wang, R.Y., Tsai, S.C., Chen, J.J., \& Wang, P.S. (2001). The simulation effects of mountain climbing training on selected endocrine responses. Chinese Journal of Physiology, 44(1), 13-18.

Zhou, X.S., Rowley, J.A., Demirovic, F., Diamond, M.P., \& Badr, M.S. (2003). Effect of testosterone on the apneic threshold in women during NREM sleep. Journal of Applied Physiology, 94, 101-107. doi: 10.1152/japplphysiol.00264.2002

Zitzmann, M. (2008). Effects of testosterone replacement and its pharmacogenetics on physical performance and metabolism. Asian Journal of Andrology, 10, 364-372. doi: 10.1111/j.1745-7262.2008.00405.x

Submitted: November 6, 2018

Accepted: December 4, 2018

Published Online First: December 13, 2018

Correspondence to:

Prof. Lana Ružić, M.D., Ph.D.

Dpt. Sport and Exercise Medicine

Faculty of Kinesiology University of Zagreb

Address: Horvacanski zavoj 15, 10000 Zagreb

Croatia

Phone: +38598380753,

E-mail: lana.ruzic@kif.hr

\section{Acknowledgments}

Special thanks to the Central Sunce Polyclinic Zagreb in which the laboratory tests were analyzed. They had a lot of understanding for the special organizational requests needed for this type of research and were available as needed. Also, our thanks go to Goran Lišnjić who measured $\mathrm{SpO}_{2}$ during the trip and took notes about status of the subjects.

Financial/Material Support Statement: Supported by a grant from the University of Zagreb.

Disclosures: None 